\title{
SPECTRUM OF HISTOPATHOLOGICAL PATTERNS OF DUODENAL BIOPSIES IN PATIENTS WITH UNEXPLAINED ANAEMIA AND CHRONIC DIARRHEA AND THEIR CORRELATION WITH ENDOSCOPIC FINDINGS AND SEROLOGICAL MARKERS
}

\author{
Muhammad Awais Yasin, Muhammad Asif Farooq, Nasir Uddin, Bushra Parveen, Asma Asghar, Javeria Ahsan
}

Combined Military Hospital Lahore/National University of Medical Sciences (NUMS) Pakistan

\section{ABSTRACT}

Objective: To evaluate different histopathological patterns and correlate them with indications, findings of Esophagogastroduodenoscopy Esophago-gastro-duodenal (EGD) and serological markers in patients presenting of unexplained anemia and chronic diarrhea.

Study Design: Cross sectional study.

Place and Duration of Study: Departments of Pathology and Gastroenterology, Combined Military Hospital Lahore Pakistan, from Jul to Dec 2020.

Methodology: Histopathological patterns of endoscopic duodenal biopsies, submitted for evaluation of unexplained anemia and chronic diarrhea were studied. Hemoglobin and anti-tTG levels were recorded. Adults with history of unexplained diarrhea and anaemia were included. Biopsies with malignant diagnosis or unfit for evaluation were excluded. Histopathological patterns were correlated with indications and findings of Esophagogastroduodenoscopy and serological markers of celiac disease.

Results: The most common indication for Esophagogastroduodenoscopy in 145 patients was chronic diarrhea. Upper gastrointestinal endoscopy in 2/3rd of patients revealed no pathology. Histopathological patterns of duodenal biopsies revealed only $15 \%$ cases suggestive of celiac disease. Only 12 patients were suggestive of celiac disease both on Esophagogastroduodenoscopy and histopathology combined. Half of patients with anti tTG level $>100 \mathrm{u} / \mathrm{ml}$, showed histopathological features of celiac disease on. There was no correlation between histopathological patterns, indications of Esophagogastroduodenoscopy, morphology of Esophagogastroduodenoscopy and serological markers of celiac disease.

Conclusion: Indications for Esophagogastroduodenoscopy, Esophagogastroduodenoscopic findings and histopathological patterns cannot diagnose celiac disease alone.

Keywords: Anaemia, Celiac disease, Chronic diarrhoea, Esophagogastroduodenoscopy.

How to Cite This Article: Yasin MA, Farooq MA, Uddin N, Parveen B, Asghar A, Ahsan J. Spectrum of Histopathological Patterns of Duodenal Biopsies in Patients with Unexplained Anemia and Chronic Diarrhea and Their Correlation with Endoscopic Findings and Serological Markers. Pak Armed Forces Med J 2021; 71(5): 1893-1896. doi: https://doi.org/10.51253/pafmj.v71i5.6145

\footnotetext{
This is an Open Access article distributed under the terms of the Creative Commons Attribution License (https://creativecommons.org/licenses/by-nc/4.0/), which permits
} unrestricted use, distribution, and reproduction in any medium, provided the original work is properly cited.

\section{INTRODUCTION}

Esophagogastroduodenoscopy endoscopy (EGD) is a caveat in diagnosing many gastrointestinal diseases. It allows visual inspection and an opportunity to obtain specimens for histopathological evaluation. Evaluation for anaemia and chronic diarrhoea are two common indications where EGD with duodenal and/ or gastric biopsies is advised. Gastrointestinal causes of anemia include are variety of diseases along with the alimentary tract and liver diseases. Duodenal biopsies are recommended where there is suspicion of malabsorption as a contributory cause of anaemia. ${ }^{1}$ Clinical findings, inspection of duodenal mucosa and its correlation with serological and histopathological findings of endoscopic biopsies are all utilized to reach at definite aetiology of malabsorption and anaemia.2,3

Correspondence: Dr Muhammad Awais Yasin, Resident Gastroenterology, Combined Military Hospital, Lahore Pakistan

Received: 19 Jan 2021; revision received: 12 Mar 2021; accepted: 24 Mar 2021
Anaemia has been defined as low haemoglobin with different cut off values in literature. ${ }^{4}$ Approach to evaluation of anaemia includes estimation of hematological parameters most important being mean corpuscular volume $(\mathrm{MCV})$. Among the three types of anaemia based on MCV, duodenal biopsies are most helpful in evaluation of microcytic anaemia with low iron levels indicated by low serum ferritin. ${ }^{5}$ Apart from microcytic anemia, duodenal biopsies are an important tool for evaluation of chronic diarrhoea. Chronic diarrhoea is classically defined as diarrhoea lasting $>4$ weeks. ${ }^{6,7} \mathrm{It}$ results in malabsorption syndrome and anaemia which can be either microcytic or macrocytic.

Celiac disease is an important cause of malabsorption and anemia. Iron deficiency anaemia is a significant feature of celiac disease. Patients can also present with magaloblastic anemia as a late manifestation of disease due to malabsorption of vit B12 and folate irrespective of age, sex and ethnicity. ${ }^{8}$ Endoscopic fin- 
dings provide clue for the disease, where as histopathologic features of the celiac disease manifest infiltration of intra epithelial lymphocytes, hypertrophy of crypt leading to villi atrophy. ${ }^{9}$ Objective of our study was to correlate histopathological findings of biopsies with indications of EGD, findings of EGD and serological markers for diagnosing celiac disease.

\section{METHODOLOGY}

This cross-sectional study was carried out at the departments of Pathology and Gastroenterology, Combined Military Hospital (CMH) Lahore Pakistan, from July to December 2020. Approval was taken from ERB (ethics review board) (No:217/2020). All endoscopic duodenal biopsies submitted to Histopathology department of $\mathrm{CMH}$ Lahore for evaluation of anemia and chronic diarrhea were retrieved from lab records. The study sample size was estimated using a single population proportion formula using Australian Bureau of Statistics online sample size calculator, which was calculated with following assumptions: $95 \%$ confidence level, $5 \%$ margin of error and $0.7 \%$ expected proportion of celiac disease on biopsy among patients presenting with chronic diarrhea, based on a similar study findings by Singh et al ${ }^{10}$. Given these assumptions the required sample size was determined to be 27 . As the sampling technique used was consecutive, sample size was increased to 145 patients. Biopsies fulfilling inclusion criteria were selected. Endoscopic findings were confirmed from endoscopy record book. Hemoglobin levels and anti-tTG levels of these patients were recorded. Consent for using lab data for research purpose was obtained from patients while submitting histopathology specimens.

Inclusion Criteria: The adult patients, aged $>12$ years having history of chronic diarrhea, anaemia and chronic diarrhea along with anaemia for duration of $>6$ months were included in the study

Exclusion Criteria: Patients who did not consent for usage of their specimens for research work were not included in the study. Biopsies showing diagnosis of malignancy, biopsy material too scanty $(<5$ villi available) or blocks not available and/or showing processing/fixation artifacts were excluded.

All patients had underdone oesophago-gastroduodenoscopy (EGD) through magnification Olympus gastroscope (GF 180, Olympus, Japan) by gastroenterologist. Four specimen biopsies, 2 from $1^{\text {st }}$ and 2 from $2^{\text {nd }}$ part of duodenum were taken. Biopsies were fixed in $10 \%$ buffered formal saline for $4-8$ hours and then processed in Leica automated processor for 6 hours.
Specimens were embedded in paraffin and blocks were made. Five micron thick sections were cut by microtome and stained by hematoxylin and eosin. Sections were mounted on slides and cover slips were applied for microscopic examination. Histopathological patterns of biopsy specimens were studied under microscope by two different histopathologists independently. Difference of opinion was discussed to reach at final opinion in a few case.

Results were entered and anlysed using SPSS- 25. Frequencies and percentages were obtained for indications and findings of EGD and histopathology findings. Correlation of indications, EGD findings and serological findings with histopathological patterns were calculated by Spearman method. The $p$-value of $\leq 5$ was considered significant.

\section{RESULTS}

A total of 168 duodenal biopsies were received, but our study included only 145 patients who fulfilled inclusion criteria. Among these, 101 (69.7\%) were male and $44(30.3 \%)$ were female patients. Age range was $13-72$ years with mean age $39.8 \pm 15.8$ years. The most common indication for EGD in our study was chronic diarrhoea (61\%). Frequencies of indications for EGD and histopathological findings are shown in the Table-I.

Table-I: Findings of Esophagogastroduodenoscopy (EGD) and Histopathological pattern of biopsies $(n=145)$.

\begin{tabular}{l|c}
\hline $\begin{array}{l}\text { Esophagogastroduodenoscopy (EGD) } \\
\text { Endoscopic Findings }\end{array}$ & $\mathbf{n}(\mathbf{\%})$ \\
\hline Typical Findings of Celiac Disease & $31(21.4)$ \\
\hline Non-specific Findings & $19(13.1)$ \\
\hline Unremarkable study & $95(65.5)$ \\
\hline \multicolumn{1}{l}{ Histopathologic Findings } & $23(15.9)$ \\
\hline $\begin{array}{l}\text { Diffuse severe villous abnormality with } \\
\text { crypt hyperplasia }\end{array}$ & $2(1.4)$ \\
\hline $\begin{array}{l}\text { Variable villous abnormality with crypt } \\
\text { hypoplasia }\end{array}$ & $26(17.9)$ \\
\hline Non-specific variable villous abnormality & $16(11)$ \\
\hline $\begin{array}{l}\text { Variable villous abnormality with specific } \\
\text { diagnosis }\end{array}$ & $78(53.8)$ \\
\hline Unremarkable study &
\end{tabular}

On upper GI endoscopy 2/3rd (95/145) of patients did not reveal any pathology. Histopathology of duodenal biopsies suggestive of celiac disease was found in only 23/145 (15\%) of cases. Microscopy was unremarkable in 78/145 (53.7\%) of cases. Indications for EGD were anaemia in 57( $39.3 \%)$, chronic diarrhea in $62(42.8 \%)$ and combined chronic diarrhea and anaemia in $26(17.9 \%)$ cases of study population. There was a negative correlation of histopathological findings 
with indications of Esophagogastroduodenoscopy and Esophagogastroduodenoscopic findings by Pearson's coefficient $r=0-.003$ and -0.15 respectively, shown in the Table-II.

Table-II: Pearson's correlation of histopathological findings.

\begin{tabular}{|c|c|c|}
\hline Parameters & $\begin{array}{c}\text { Pearson Correlation } \\
\text { Co-efficient } \& p \text {-value }\end{array}$ & Values \\
\hline \multirow{2}{*}{ Age (In years) } & Pearson Correlation Co-efficient & 0.080 \\
\hline & $p$-value & 0.660 \\
\hline \multirow{2}{*}{ Gender } & Pearson Correlation Co-efficient & 0.034 \\
\hline & $p$-value & 0.926 \\
\hline \multirow{2}{*}{ Indication } & Pearson Correlation Co-efficient & -0.003 \\
\hline & $p$-value & 0.160 \\
\hline \multirow{2}{*}{$\begin{array}{l}\text { Esophagogastro } \\
\text { duodenoscopic } \\
\text { findings }\end{array}$} & Pearson Correlation Co-efficient & -0.105 \\
\hline & $p$-value & 0.000 \\
\hline \multirow{2}{*}{ Heamoglobin } & Pearson Correlation Co-efficient & 0.211 \\
\hline & $p$-value & 0.022 \\
\hline \multirow{2}{*}{ Anti tTG Level } & Pearson Correlation Co-efficient & -0.339 \\
\hline & $p$-value & 0.130 \\
\hline
\end{tabular}

\section{DISCUSSION}

Celiac disease is autoimmune in nature. It is a gluten-sensitive enteropathy in genetically predisposed individuals to gluten intolerance. Gluten, a toxic component of cereal grains, affects proximal intestine more than distal ${ }^{11}$. The small bowel mucosal responses to injury are limited. Recognition of these response patterns can be useful in differential diagnosis. In term" severe villous abnormality" intestinal mucosa is flat showing no villi. In term "variable villous abnormality" the villi are either only focally flat or are less than flat. Pattern of abnormal small-bowel architecture are: 1) diffuse severe villous abnormality and crypt hyperplasia ${ }^{2}$. Variable villous abnormalities and crypt hypoplasia ${ }^{3}$. Non-specific variable villous abnormality, usually not flat ${ }^{4}$. Variable villous abnormalities with specific diagnostic changes ${ }^{12}$. Diagnosis of the disease involves high index of suspicion and correlation of EGD findings and specific serologic markers with histopathological findings of duodenal mucosa. Diagnosis of celiac disease can be made if high titres of celiac specific serologic markers are found in immune-competent patients with diffuse villous abnormality and crypt hyperplasia on microscopy of duodenal biopsy.

We studied 145 patients of unexplained anemia and chronic diarrhea, who had undergone duodenal biopsies. They were $69.7 \%$ males and $30.3 \%$ females. Male to female ratio was 2.3:1. Reported data on celiac disease shows male to female ratio to be 1:2 with some of the studies having consensus of 1:13,14.

Analysis of indications of EGD with histopathological patterns revealed that on microscopy, findings suggestive of celiac disease are mostly found in anaemic patients (11\%) as compared to patients with chronic diarrhea (8\%) and indications of EGD and histopathology have negative correlation with Pearson's coefficient $r=-0.003$. Analysis of EGD findings with histopathology revealed that only $(8.27 \%)$ patients were suggestive of celiac disease on both macroscopy and microscopy (Figure-2). Histopathology and esophagogastroduodenoscopic findings have strong negative correlation with Pearson's coefficient $\mathrm{r}=-0.105$. AntitTG serology was available for only 48/145 (33.1\%) patients and 31/48 patients had anti-tTG level $<20 \mathrm{u} /$ $\mathrm{ml}$, out of which 4 patients had findings of celiac disease on histopathology, 9/48 had anti tTG level between 20-100 u/ml, out of which 2 patients were suggestive of celiac disease on histopathology. Eight out of forty eight patients had anti-tTG level $>100 \mathrm{u} / \mathrm{ml}$ out of which 4 patients were confirmed to have celiac disease on histopathology. Age range of patients showing classical features of celiac disease on histopathology was 19-70 years in our study. However most of the patients were in the age range of $25-50$ years. Male to female ratio was 2.3:1 in our study.

The frequency of celiac disease reported in European counties is $1 \%$ with the highest prevalence in Finland (2.4\%). In Asia, a particularly high prevalence of celiac disease has been reported from Indian Punjab where wheat has been used as a staple diet for generations ${ }^{15}$. In present study common indications of upper GI endoscopy were chronic diarrhoea $(42.8 \%)$, and anaemia $(39.3 \%)$, and chronic diarrhoea along with anaemia, of which $13 \%, 19.29 \%$ and $15.38 \%$ patient were diagnosed with celiac disease on histopathological examination, respectively. This reveals that celiac disease is mostly found in anaemic patients $(19.29 \%)$ in our study, while worldwide prevalence of celiac disease in patients with iron deficiency anaemia varies from $0-5 \%$. Grisolano and colleagues reported that its frequency was $8.7 \%(\mathrm{n}=103)^{16,17}$. Broide, et al have recommended that patients with unexplained iron deficiency anaemia should be worked up for celiac disease by histopathology of biopsies ${ }^{18}$. In our study, 95 (65.5\%) patients had unremarkable findings on EGD, but 10 $(6.8 \%)$ patients were diagnosed as celiac disease on histopathology. It reveals that EGD alone has lower sensitivity and absence of endoscopic findings does 
not exclude celiac disease. It is therefore recommended that microscopic examination of biopsies should be done for conclusive diagnosis. Similar findings have been reported by Manpreet et al and other international studies as well19-21. Only $12.5 \%$ patient with anti tTG level $>100 \mathrm{u} / \mathrm{ml}$, had unremarkable study on microscopy while $50 \%$ patients had celiac disease on histopathology. On the other hand, $48.3 \%$ patients with anti tTG level $<20 \mathrm{u} / \mathrm{ml}$ had unremarkable study on microscopy and 13\% were diagnosed with celiac disease on histopathology.

According to international studies, IgA levels are low in $0.2 \%$ of general population and $2 \%$ of celiac disease patients who have diagnosis of severe villous abnormality with crypt hyperplasia on histopathology but negative serology should be worked up for other diseases which also cause mucosal abnormalities or should be checked for IgA, IgG- tTG or IgGD GP levels before conclusion 22,23 .

Our findings showed no positive correlation between clinical symptoms, indications and findings of EGD, celiac serology and histopathological study. Our results are in agreement with a study conducted in Iran $^{24}$. Therefore, it is recommended that all patients with unexplained anaemia, chronic diarrhoea and weight loss should undergo EGD. Biopsies for histopathological examination must be taken to reach at a conclusive diagnosis. However, our study has certain.

\section{CONCLUSION}

Indications for EGD, EGD findings and histopathological patterns can not diagnose celiac disease alone. Higher levels of anti tTG levels are highly suggestive of celiac disease. Patients with unexplained anemia should be worked up with EGD and histopathological evaluation to rule out celiac disease.

\section{LIMITATION OF STUDY}

Like a smaller sample size because of COVID-19 pandemic during the whole study period. Male patients were more than females as already explained. In addition, we did not investigate any of the patients for deficiencies of IgA, IgG HLA DQ2/DQ8 levels.

\section{Conflict of Interest: None.}

\section{Authors' Contribution}

MAY: Concept and design, MAF: Proof reading, NU: Proof reading, BP: Concept, design and data interpretation, AA: Data collection and statistics, JA: Data collection.

\section{REFERENCES}

1. Gonen C, Yilmaz N, Yalcin M, Simsek I, Gonen O. Diagnostic yield of routine duodenal biopsies in iron deficiency anaemia: a study from Western Anatolia. Eur J Gastroenterol Hepatol 2007; 19(1): 37-41.
2. Balasubramanian P, Badhe BA, Ganesh RN, Panicker LC, Mohan P. Morphologic Spectrum of Duodenal Biopsies in Malabsorption: A Study from Southern India. J Clin Diagn Res 2017; 11(7): EC17-EC21.

3. Abdulkarim AS, Murray JA. Review article: The diagnosis of coeliac disease. Aliment Pharmacol Ther 2003; 17(8): 987-995.

4. Cappellini MD, Motta I. Anemia in clinical practice-definition and classification: does hemoglobin change with aging? Semin Hematol 2015; 52(4): 261-269.

5. Cascio MJ, DeLoughery TG. Anemia: evaluation and diagnostic tests. Med Clin North Am 2017; 101(2): 263-284.

6. Schiller LR, Pardi DS, Spiller R, Semrad CE. Gastro 2013 APDW/ WCOG Shanghai working party report: chronic diarrhea: definition, classification, diagnosis. J Gastroenterol Hepatol 2014; 29(1): 6-25.

7. Schiller LR, Pardi DS, Sellin JH. Chronic Diarrhea: Diagnosis and Management. Clin Gastroenterol Hepatol 2017; 15(2): 182-193.

8. Kowalski K, Mulak A, Jasińska M, Paradowski L. Diagnostic challenges in celiac disease. Adv Clin Exp Med 2017; 26(4): 729-737.

9. Nikzamir M, Nejad MR, Sadeghi A, Moradi A. The correlation between endoscopy manifestations and pathology outcome for diagnosis of celiac disease. Int J Celiac Dis 2017; 5(3): 101-103.

10. Singh P, Arora A, Strand TA, Leffler DA, Catassi C, Green PH, at al. Global prevalence of celiac disease: Systemic review and meta analysis . Clin gastroenterol Hepatol 2018: 16(6); 823-836.

11. Lima VMD, Gandolfi L, Pires JADA, Pratesi R. Prevalence of celiac disease in dyspeptic patients. Arq Gastroenterol 2005: 42(3); 153-156.

12. Mills SE, Greenson JK, Hornik JS. Stenberg's Diagnostic Surgical Pathology, Feb 2015: $6^{\text {th }}$ Edition, [Internet] Available from: https:// www.amazon.com/Sternbergs-Diagnostic-Surgical-PathologyStacey-ebook/dp/B00SK5XK8GHashim

13. ZA, AL-Namil SA. The value of endoscopic biopsies from first and second parts of duodenum in the diagnosis of celiac disease in correlation with a serological test. Bas J Surg 2017; 23(2): 4-39.

14. Ciclitira PJ. AGA Technical Review on Celiac Sprue. J Gastroenterol 2001; 120(6): 1526-1540.

15. Feldman M, Friedman LS, Brandt LJ, Chung RT, Robin DT,Wilcox CM. Sleisenger and Fordtran's Gastrointestinal and Liver Disease. $11^{\text {th }}$ Edition June 2020, [Internet] Available from: https://www. elsevier.com/books/sleisenger-and-fordtrans-gastrointestinal-andliver-disease-2-volume-set/feldman/978-1-4557-4692-7

16. Karnam US, Felder LR. Prevalence of occult celiac disease in patients with iron-deficiency anemia. South Med J 2004; 97(1): 30-34.

17. Grisolano SW, Oxentenko AS, Murray JA, Burgart LJ, Dierkhising RA. The usefulness of routine small bowel biopsies in evaluation of iron deficiency anaemia. J Clinic Gastroenterol 2004; 38(9): 756-760.

18. Broide E, Matalon S, Kriger-Sharabi O, Richter V, Shirin H, Leshno $M$. Cost effectiveness of routine duodenal biopsies in iron deficiency anemia. World J Gatroenterol 2016; 22(34): 7813-7823.

19. Manpreet K, Singh BT, Mridu M, Rahul M, Sonam S. Correlation between histopathological and endoscopic findings of non-malignant gastrointintestinal lesions. J Pathol nep 2018; 8(2): 1289-1296.

20. Cammarota G, Fedeli P, Gasbarrini A. Emerging technologies in upper gastrointestinal endoscopy and celiac disease. Nat Clin Pract Gastroenterol Hepatol 2009; 6(1): 47-56.

21. Dickey W. Endoscopic markers for celiac disease.Nat Clin Pract Gastroenterol Hepatol 2006; 3(10): 546-51.

22. Hammer ST, Greenson JK. The clinical significance of duodenal lymphocytosis with normal villous architecture. Arch Pathol Lab Med 2013; 137(9): 1216-1219.

23. Lewis NR. Meta-analysis deamidatedgliadin peptide antibody and tissue transglutaminase antibody compared as screening test for celiac disease. Aliment Pharmicol Ther 2010; 31(1): 73-81.

24. Chellat H, Salihoun M, Kabbaj N, Amrani L, Serraj I, Chaoui Z, et al. Diagnostic yield of routine duodenal biopsies in iron deficiency anemia for celiac disease diagnosis. Int Sch Res Notices 2013, [Internet] Available from: http://dx.doi.org/10.5402/2013/769519 (Accessed on December 15, 2020) 